\title{
INCREASING EFFICIENCY OF FLEXIBLE MANUFACTURING SYSTEMS BASED ON COMPUTER PRODUCT GROUPING
}

\author{
Bogdan Palchevskyi ${ }^{1}$, Antoni Swic ${ }^{2 *}$, Helena Krestyanpol ${ }^{1}$ \\ 1 Lutsk National Technical University, Lvivska St. 75, Lutsk, Ukraine \\ 2 Lublin University of Technology, Nadbystrzycka 36, 20-618 Lublin, Poland \\ * Corresponding Author's e-mail: a.swic@pollub.pl
}

Received: 2018.04.18 Accepted: 2018.05.15 Published: 2018.06.01

\begin{abstract}
The central problem of the paper is grouping details in the conditions of FMS (flexible manufacturing system). The criteria for forming rational detail groups were identified and. The statistical analysis of details characteristics was based on the database of products for the electronic industry. The paper proposes a mathematical method of grouping using accumulated data on the processing objects, which employs the grouping criteria. By employing such an approach we are presented with details grouped according to normative indicators of FMS equipment loading or minimum loss on their readjustment within the group of technological adjusting for every robotic technological complex (RTC).
\end{abstract}

Keywords: classification, flexible production systems, readjustment, robotic technological complex, grouping technological processes readjustment optimization

\section{INTRODUCTION}

Given the wide variety of existing constructional forms of details governed by a multitude of technical requirements, and considering the plethora of different methods for processing identical elements of details for different types of technological equipment, it is unsurprising that it requires employing multiple-dimensional technological solutions.

It is particularly typical for the work conditions of flexible manufacturing systems (FMS). Therefore, what is regarded as the key task in designing technological processes for the FMS conditions is their unification. Grouping technological processes constitutes an obligatory stage preceding the development of unification processes according to $[1,2]$.

Grouping details enables creating specialized workplaces and rational optimisation of equipment engagement. If a machine shows high technological capabilities, the connection of detail construction with the manufacturing technology weakens. There- fore, in such cases, a complex detail is not created, but a defined set of features allows combining different details into one classification group.

This paper considers the task of increasing economic efficiency of FMS for mechanical sharpening of about 40 typical sizes of details with an annual production program of 450,000 pieces. FMS was developed on the basis of numerically controlled lathes, each equipped with a loading robot, forming an independently working robotized technological complex (further RTC). The FMS was organized in the form of a section with RTC, adjacent to an automatic warehouse. Every working position of the FMS section was specialized for processing a certain group of detail operations of RTC by means of technological group debugging. The grouping of detail operations and the specialization of each RTC to the corresponding group of detail operations should be carried out in such a way that their volume of detail operations is sufficient to ensure the loading of RTC. In addition, it is necessary to reduce the duration of readjustment operations. 


\section{LITERATURE OVERVIEW}

The question of automation of classification and coding of production objects based on their design and technological features is paramount to creation of FMS $[3,4]$; and yet, to date, it has not been sufficiently elaborated.

In the conditions of small-serial and serial production the most prevalent method for grouping details is according to the type of equipment used for processing, i.e. the unity of technological equipment $[2,5,6]$. In the same stance we should note the principle of forming groups by constructing matrices of details-machine tools proposed by [3]. This principle is based on the formation of a matrix, in which the columns are the details, and lines-production equipment. The paper [7] formulated a mathematical problem on the formation of a finite number of groups of product and production equipment. However, practice has shown that no algorithm exists that would ensure the optimal solution to the problem in question [8-9].

In most cases the process of classification and coding of information about details for automated technological designing is carried out by an engineer-technologist manually, by visual analysis of geometrical form of details, design-engineering requirements and physico-mechanical properties of materials [4]. This leads to an increase of technological preparation to production and becomes ineffective for a wide range of manufactured products.

Therefore, determining factors of detail grouping may be given as follows: type and number of tools used for processing, machine tool layout, the type of fixture, the community of billets, dimensional proximity. In addition, in order to ensure the work of industrial robot it is necessary to carry out a structural and technological analysis of details in terms of their alignment to ensure the unity of the auxiliary RTC equipment, namely the configuration and size of cassette stores, a set of jobs, etc. With the wide range of manufactured products, the time for re-adjustment of equipment from one detail type to another becomes crucial.

As noted in [10], the problem of automated classification and product grouping still remains unresolved. The paper highlights the actual character of all research works aimed at employing automation of classification and grouping of production objects using modern information technologies with a view to increasing the economic efficiency of FMS.

\section{Purpose of work}

The purpose of this work is to develop methodology for automating the procedure of grouping details using modern methods of cluster analysis on the basis of technical criteria.

\section{RESULTS OF RESEARCH}

\section{Grouping processing objects under FMS conditions}

Classification in the conditions of FMS is implemented for grouping various-purpose objects of production and designed towards unification and typification of technological processes and types of technological equipment operating in the FMS. There are several conditions that determine the features and tasks of classification in grouping objects in the FMS. The basis for selection and grouping is the use of the following data regarding $[2,5,6]$ :

- movement of objects around the main workstations of RTC;

- transport-storage system of RTCFMS

- the system of loading-unloading details, tools, etc. in RTC;

- the operational control systems.

The process of classification consists of partitioning the elements of plural $\mathbf{B n}$ on totality of outstanding subsets, which cover all plural Bn. Each subset corresponds to a class uniting the elements of plural $\mathbf{B n}$ with matching properties in the $N$-th parameter space. This class is obtained from technological debugging grouping. Separate classes of product groups are formed on the basis the most important classification features, such as the use of fixture for the cartridge ware or chuck. Other classification features allow expanding the amount of classes, for example, the type of cassette store in the RTC.

The process of automatic grouping of detail operations in the creation of technological debugging group is developed with a custom mathematical model (Table 1).

The coefficient of similarity of the detail operations in question to the g-class is determined by the expression:

$$
K_{\text {sim }}=\frac{\sum_{i, j=1} F_{i} \cdot C_{i j}}{\sum_{i=1} F_{i}}
$$


Table 1. Mathematical model for grouping products within the technological debugging group of specialized RTC

\begin{tabular}{|c|c|c|c|c|c|c|c|c|c|c|c|}
\hline \multirow{3}{*}{ Operations } & \multicolumn{11}{|c|}{ Debugging elements of RTC } \\
\hline & Chuck & Collet & Grip & Magazine & $\begin{array}{l}\text { Control } \\
\text { device }\end{array}$ & $\begin{array}{c}\text { Instrument } \\
1\end{array}$ & \begin{tabular}{|c|} 
Instrument \\
2 \\
\end{tabular} & & \begin{tabular}{|c|} 
Instrument \\
$\mathrm{i}$
\end{tabular} & & $\begin{array}{c}\text { Instrument } \\
\mathrm{N}\end{array}$ \\
\hline & $\mathrm{F}_{1}$ & $\mathrm{~F}_{2}$ & $\mathrm{~F}_{3}$ & $\mathrm{~F}_{4}$ & $\mathrm{~F}_{5}$ & $\mathrm{~F}_{6}$ & $\mathrm{~F}_{7}$ & $\cdots$ & $\mathrm{F}_{\mathrm{i}}$ & $\cdots$ & $\mathrm{F}_{\mathrm{N}}$ \\
\hline $\mathrm{b}_{1} \mathrm{n}_{1}$ & 0 & & O & O & O & O & O & $\ldots$ & O & $\ldots$ & O \\
\hline $\mathrm{b}_{1} \mathrm{n}_{2}$ & 0 & & 0 & & 0 & & O & $\cdots$ & O & $\ldots$ & O \\
\hline $\mathrm{b}_{2} \mathrm{n}_{1}$ & - & & ○ & ○ & & & & $\cdots$ & & $\cdots$ & \\
\hline$\cdots$ & $\cdots$ & $\cdots$ & $\cdots$ & $\cdots$ & $\cdots$ & $\cdots$ & $\cdots$ & $\cdots$ & $\cdots$ & $\cdots$ & $\cdots$ \\
\hline$b_{i} n_{j}$ & & 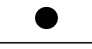 & 0 & 0 & 0 & 0 & 0 & $\ldots$ & & $\ldots$ & \\
\hline$\ldots$ & $\ldots$ & $\ldots$ & $\cdots$ & $\ldots$ & $\ldots$ & $\ldots$ & $\cdots$ & $\ldots$ & $\ldots$ & $\cdots$ & $\ldots$ \\
\hline$b_{n} n_{m}$ & & 0 & 0 & & 0 & & 0 & $\ldots$ & 0 & $\ldots$ & 0 \\
\hline
\end{tabular}

\section{Notes:}

$\{\boldsymbol{F}\}=\left(F_{1}, F_{2} \ldots F_{N}\right)-$ plural classification features of g-class;

$\{B n\}=\left(b_{1} n_{1}, b_{1} n_{2}, b_{2} n_{1}, \ldots, b_{n} n_{m}\right)-$ plural objects of classification - detail operations; $C_{i j}$ - a variable that takes following values:

$C_{i j k}=\left\{\begin{array}{l}1, \text { if no re-adjustment is required at implementation of this detail operation of } i \text {-element } \\ 0-\text { otherwise }\end{array}\right.$

Analysis of RTC technological subsystem readjustment times was based on sharpening time determined for all details in the instruments group.

An algorithm for grouping particular operations was developed for RTC in the FMS.

Technological preparation of group production involves grouping detail operations and development of processes for readjustment of each RTC in the FMS $[5,8,11]$.

In order to reduce the loss of time for readjustment, it necessary to carry out the specialization of debugging the RTC to a group of detail operations. Quantitatively, the level of specialization is characterized by the coefficient of technological flexibility of RTC:

$$
G=\frac{1}{1+\sum_{i=1}^{n} \frac{t_{\text {read } i}}{t_{0 i} p_{i}}}\left(1-\frac{1}{n}\right)
$$

where: $n$ - the number of detail types; $t_{\text {read }, i}-$ time of readjustment for processing $i$-details; $t_{0 i}$ and $p_{i}-$ time for processing and size of a batch of $i$-details.

The basis for constructing a general grouping algorithm includes the following positions [10]:

- grouping is based on the smallest time spent on readjusting the equipment for one group of detail operations;

- the number of detail operations in the group for each RTC is accumulated to the level of its loading, which is sufficient for the normalized value of the coefficient of use.

For RTC turning the adaptation to a new product consists of readjusting the tool kit, machine tool clamping device, the capture of the taps, the cassette drive of the billets, the control device, and the readjustment times take the following form:

$T_{\text {read }, i}+a t_{\text {adap }}+\eta t_{\text {tool }}+t_{\text {prog }}+\beta t_{\text {capt }}+\gamma t_{\text {cass }}+\lambda t_{\text {cont }}$

where: $\eta$ - the number of instruments, replaced in readjustment; $\alpha, \beta, \gamma, \lambda$ - logical coefficients equal to zero in the absence of corresponding readjustment, otherwise equal to 1 .

An algorithm for grouping details is designed for general processing jobs on one RTC and takes into account readjustment time of both technological and transport subsystems of RTC (Fig. 2). The output data (block 1) is a matrix of working capacities $\mathrm{M}\left[\mathrm{t}_{0}\right]$ of all $b i$ - those detailed operations (i-operation above $b$-detail).

Furthermore, in the algorithm the matrix of readjustment of $\mathrm{M}\left[\mathrm{t}_{\text {read }}\right]$ (block 2) for each group debugging is formed and the groups of detail operations which do not require any readjustment, i.e. for which $t_{\text {read }}=0$, (block 3) are allocated.

Having selected a group of details that does not require readjustment, it is assigned the sequence number of $g=1, G$ (block 4 ) in the increasing order : 


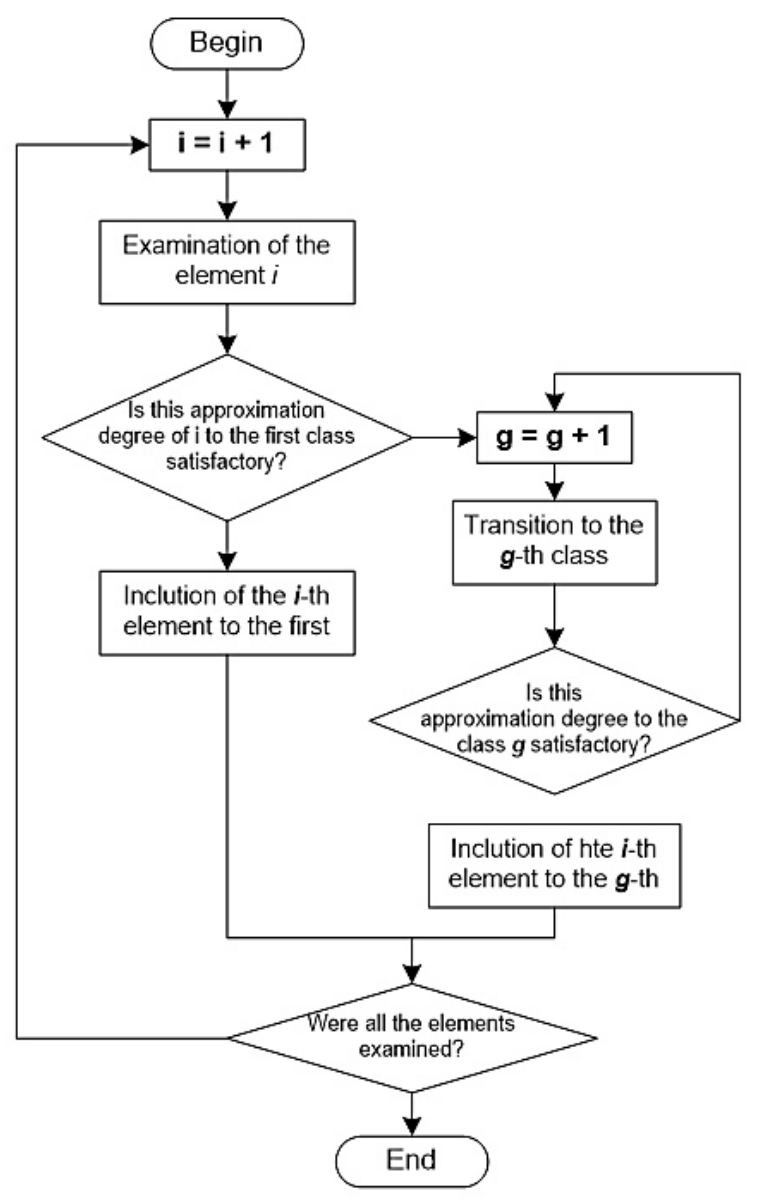

Fig. 1. Block diagram of the algorithm for processing the mathematical model of grouping

$$
A_{i g}=t_{\text {big }} N_{i r}+T_{\text {read big }} \frac{N_{i r}}{p_{i g}}
$$

where: $t_{b i g}$ - working capacity bi-detailed operations $g$-th group; $N_{i g}, p_{i g}-$ an annual volume of production and size of start batch of $i$-detail of $r$-groups.

The rest of detail operations, that are not included in the group, is ranked (block 5) for increasing value of $T_{\text {read bi }}$. The further additional completing of groups, beginning from the first (block 6), is true under the following conditions.

If:

$$
\sum_{i g=1}^{n g} A_{i g} \leq \Phi \cdot \eta
$$

(block 7) (here $\Phi-$ an actual annual fund of time for RTC; $\eta$ - normative load of equipment factor), then, in addition to the details, the processing of which does not need RTC readjustment, in the $g$-group, the details operations (blocks 15 and 16) in the increasing order of $T_{\text {nep big }}$ are included. Every considered detail operation is also included

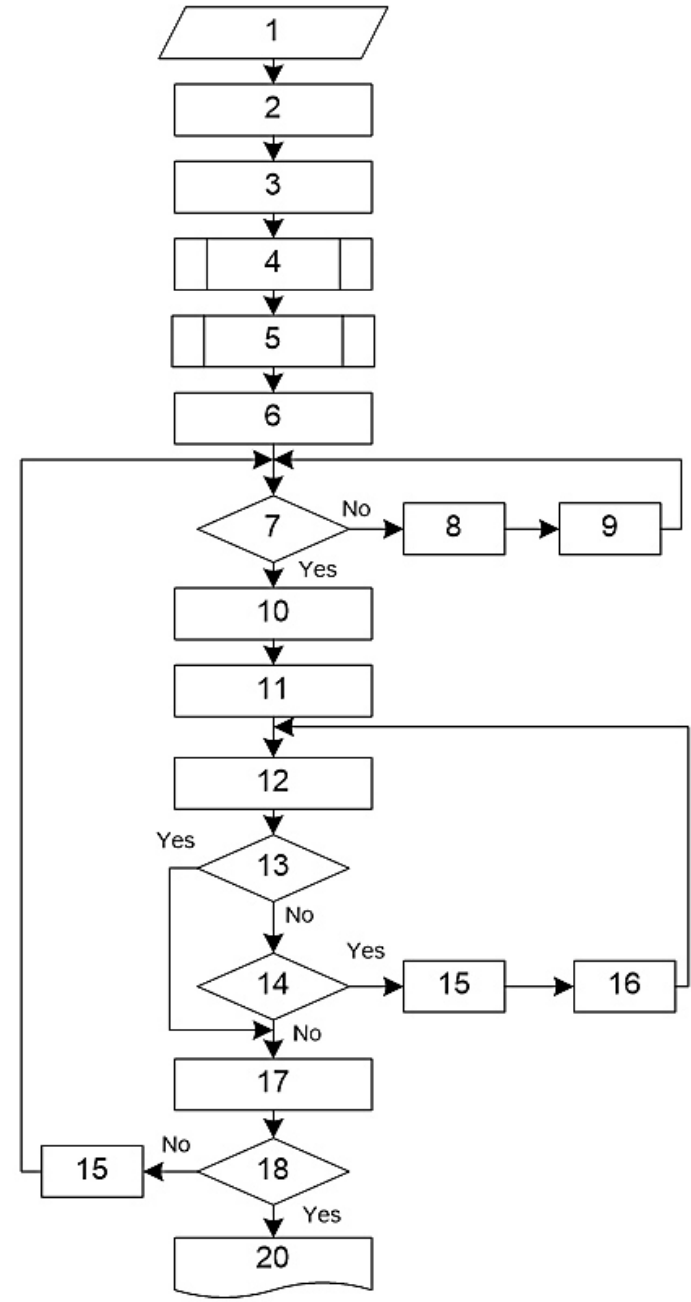

Fig. 2. An algorithm grouping details for optimization of RTC

in the composition of the $g$-group, if the calculated value coefficient of technological flexibility of $\mathrm{G}_{\mathrm{g} 2}$ after its including (block 12) is not less than the value of $\mathrm{G}_{\mathrm{g} 1}$ (block 10) before the inclusion of this detail operation into the group, that is $\mathrm{G}_{\mathrm{g} 2} \geq \mathrm{G}_{\mathrm{g} 1}$ (block 13).

1. At inclusion in $g$-th group of $i$-detail a condition must be executed (block 14):

$$
\sum_{i g=1}^{n g+1} A_{i g} \leq \Phi \cdot \eta .
$$

By default, this condition regarding the $i$-detail in a group is not included.

2. If a condition is executed:

$$
\sum_{i g=1}^{n g} A_{i g}>\Phi \cdot \eta
$$

then from $g$-th group details consistently exclude operations until the condition set in a block 7 starts to be executed. The group of $g$ will be di- 
vided in two (block 8) in such a way that one of them is fully formed. The total amount of groups here will grow on unit (block 9).

3. Subsequently, the verification is conducted to determine whether the formation of all groups of detail operations is completed, i.e. the conditions $g=G$ (block 18). If a condition is not fulfilled then the next group $(g+1)$ of detail operations is formed (block 19).

The results of formation of detail operation groups are printed (block 20).

Thus, the splitting of plural $\{\boldsymbol{B} \boldsymbol{n}\}$ detail operations into $\boldsymbol{G}$ groups simplifies the creation of a technological group adjusting RTC for this group, and the rational loading of equipment is achieved by completing each unit of equipment with the corresponding number of detail operation groups, sufficient for its normalized loading.

\section{CONCLUSIONS}

The analysis presented in our paper concludes that when grouping detail operations for the FMS conditions:

1. The runtime of detail operations included in the group exceeds the actual annual time of equipment. In this case, the formed group of detail operations should be divided and specialized equipment for each sub-group allocated, alternatively, several units of machine tools should work in parallel.

2. The runtime of detail operations is close to the actual annual equipment working time fund. This will allow allocating equipment with constant specialization.

3. The runtime of the detail operations group is insufficient for the complete loading of equipment. In this case the equipment serves a few groups of detailed operation with a view to respecialization.

As the process of group formation, which includes analysis and sorting the details, is laborintensive, an algorithm for the formation of detail groups based on the principle of finding optimal groups was developed

Automated system of grouping details is a computer system which carries out the machine analysis of data of details and the formation of detail groups showing a design and technological similarities. The system includes software and hardware. The verification of the algorithm and the developed program for grouping copper details for the production of electronic lamps showed that the cost of mechanical processing is reduced by $10-15 \%$.

\section{REFERENCES}

1. Opitz H., A classifscation System to Describe Workpiece,. Pergamon Press Ltd., Oxford, England, 1970.

2. Nieszporek T., Boral P., The technology of variable-pitch cone worms in plastic extruding presses. Metalurgija, 52(3), 363-367.

3. Boral P., Nieszporek T., Geometric analysis of plasticizing system in the extruder consisting of two cone worms. Polimery, 57(7-8), 571-576.

4. Groover M.P., Zimmers E.W., CAD/CAM: computer-aided design and manufacturing. New Jersey, Prentice-Hall, 1984.

5. Opitz H., Wiendahl H.P., Group Technology and Manufacturing Systems for Medium Quantity Production, Intern. Journal of Prod. Res., 9(1), 1971, 181-203.

6. Palchevsky B., Swic A., Krestianpol H., Computer integrated designing of flexible manufacturing systems, Lublin University of Technology, Lublin 2015.

7. Kusiak A., The generalized group technology concept, International Journal of Production Research, 25, 1987, 561-569.

8. Gola A., Świć A., Kramar V., A multiple-criteria approach to machine-tool selection for focused flexible manufacturing systems, Management \& Production Engineering Review, 2(4), 2011, 21-32.

9. Shargal M., Evaluation of search algorithms and clustering efficiency measures for machine-part matrix clustering. IIE Transactions, 27, 1995, 43-59.

10. Pukhovsky Ye.S., Grouping technological objects and solutions in the design of FMS. Bulletin of NTUU “KPI”, 6, 2009, 14-20.

11. Gola A., Swic A., Algorithm for generation of technological paths in the process of selection of machine tools, Business management, 1, 2011, 8-16.

12. Epifanov V.V., Grouping of details such as bodies of rotation using cluster analysis, Mechanician, 2, 2004, 34-38. 